\title{
The Role of Blood Osmolality and Volume in Regulating Vasopressin Secretion in the Rat
}

\author{
Fredrick L. Dunn, Thomas J. Brennan, Averial E. Nelson, and \\ Gari L. Robertson \\ From the Department of Medicine, Indiana University Medical Center and the \\ Veterans Administration Hospital, Indianapolis, Indiana 46202 and the \\ Abraham Lincoln School of Medicine and Veterans Administration West \\ Side Hospital, Chicago, Illinois 60680
}

A B S T R A C T A sensitive and specific radioimmunoassay for plasma arginine vasopressin (AVP) has been used to study the effects of blood osmolality and volume in regulating AVP secretion in unanesthetized rats. Under basal conditions, plasma AVP and osmolality were relatively constant, averaging $2.3 \pm 0.9$ (SD) $\mathrm{pg} / \mathrm{ml}$ and $294 \pm 1.4 \mathrm{mosmol} / \mathrm{kg}$, respectively. Fluid restriction, which increased osmolality and decreased volume, resulted in a progressive rise in plasma AVP to about 10 times basal levels after $96 \mathrm{~h}$. A 2-3-fold increase in plasma AVP occurred as early as $12 \mathrm{~h}$, when osmolality and volume had each changed by less than $2 \%$. Intraperitoneal injections of hypertonic saline, which had no effect on blood volume, also produced a rise in plasma AVP that was linearly correlated with the rise in osmolality $(r>0.9)$ and quantitatively similar to that found during fluid restriction (plasma AVP increased 2-4-fold with each $1 \%$ increase in osmolality). Intraperitoneal injection of polyethylene glycol, which decreased blood volume without altering osmolality, also increased plasma AVP but this response followed an exponential pattern and did not become significant until volume had decreased by $8 \%$ or more. At these levels of hypovolemia, the osmoregulatory system continued to function but showed a lower threshold and increase sensitivity to osmotic stimula-

A preliminary report of this work was published in abstract form in Clin. Res. $21: 329.1973$.

Reprint requests should be addressed to Dr. Gary L. Robertson, Endocrine Metabolic Section, Veterans Administration Hospital, 1481 West 10th Street, Indianapolis, Ind. 46202.

Received for publication 30 May 1973 and in revised form 13 August 1973. tion. We conclude that AVP secretion is regulated principally by blood osmolality but that the responsiveness of this mechanism may be significantly altered by modest changes in blood volume.

\section{INTRODUCTION}

Arginine vasopressin $(A V P)^{1}$ is a nonapeptide hormone of the posterior pituitary that causes antidiuresis in man and most other mammals. Although secretion of the hormone is known to be affected by changes in both blood osmolality and volume (1), the relative importance of these two variables in physiologic control of AVP has not been well established. This has been due largely to the lack of a suitable method for accurately measuring blood $\mathrm{AVP}$ at the low concentrations normally present under basal conditions. The development in our laboratory of a sensitive and specific radioimmunoassay for plasma AVP prompted us to reinvestigate these control mechanisms. By using techniques that permitted small changes in either blood osmolality or volume to be made independently, we have been able to quantitate the relative effectiveness of these two variables in altering AVP secretion in unanesthetized rats. Our findings indicate that, under normal conditions, small changes in osmolality are more potent than small changes in blood volume in affecting AVP secretion. However, the responsiveness of the osmoreceptor mechanism appears to be significantly altered by modest changes in blood volume, indicating a close interrela-

\footnotetext{
${ }_{1}$ Abbreviations used in this paper: AVP, arginine vasopressin; $\mathrm{BV}$, blood volume; Hct, hematocrit; PEG, polyethylene glycol; $\mathrm{P}_{A V P}$, plasma AVP; $\mathrm{P}_{\mathrm{oss}}$, plasma osmolality.
} 
tionship between the two variables in the control of AVP secretion.

\section{METHODS}

Male Sprague-Dawley rats, $150-250 \mathrm{~g}$ body wt, were maintained on ad lib food and water intake at constant temperature and humidity for at least $72 \mathrm{~h}$ before use. Three techniques were used to produce changes in blood osmolality and/or volume: $a$ ) complete fluid restriction for periods of from 12 to $96 \mathrm{~h} ; b$ ) i.p. injection of distilled water, isotonic or hypertonic saline; and c) i.p. injection of a nonabsorbable polymer, polyethylene glycol (Carbowax 4000, Union Carbide Corp., Los Angeles, Calif) dissolved at varying concentrations in hypotonic, isotonic, or hypertonic saline.

At appropriate intervals after these procedures, the rats were guillotined without anesthesia and the blood issuing from the vessels of the trunk collected in chilled heparinized tubes. Small aliquots were drawn immediately into capillary tubes for microhematocrit determinations, and the remainder centrifuged at $4^{\circ} \mathrm{C}$. The plasma was carefully aspirated and an aliquot taken for determination of the

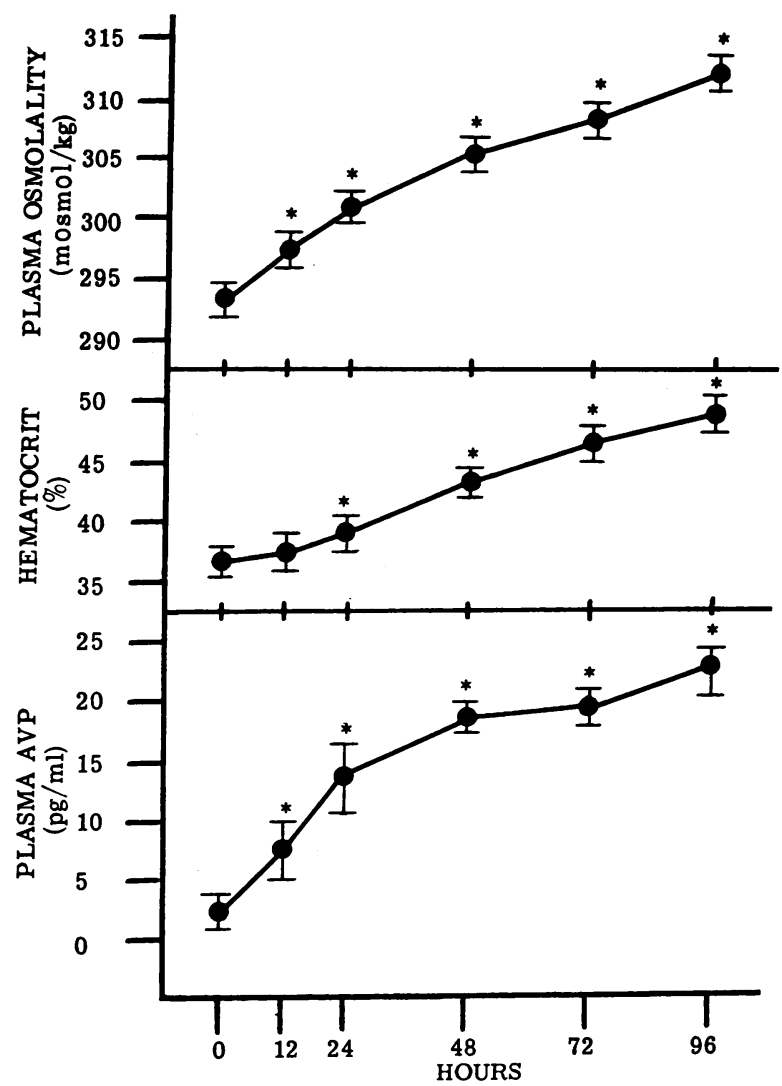

Figure 1 The effect of fluid deprivation on plasma osmolality, hematocrit, and plasma AVP. Rats were deprived of water for periods of $0,12,24,48,72$, or $96 \mathrm{~h}$, then sacrificed and the hematocrit, plasma osmolality, and AVP determined. The values at each time interval represent the mean and range of individual determinations on five animals. Asterisks indicate those values which differ significantly from the controls $(P<0.05$ by unpaired $t$-test).

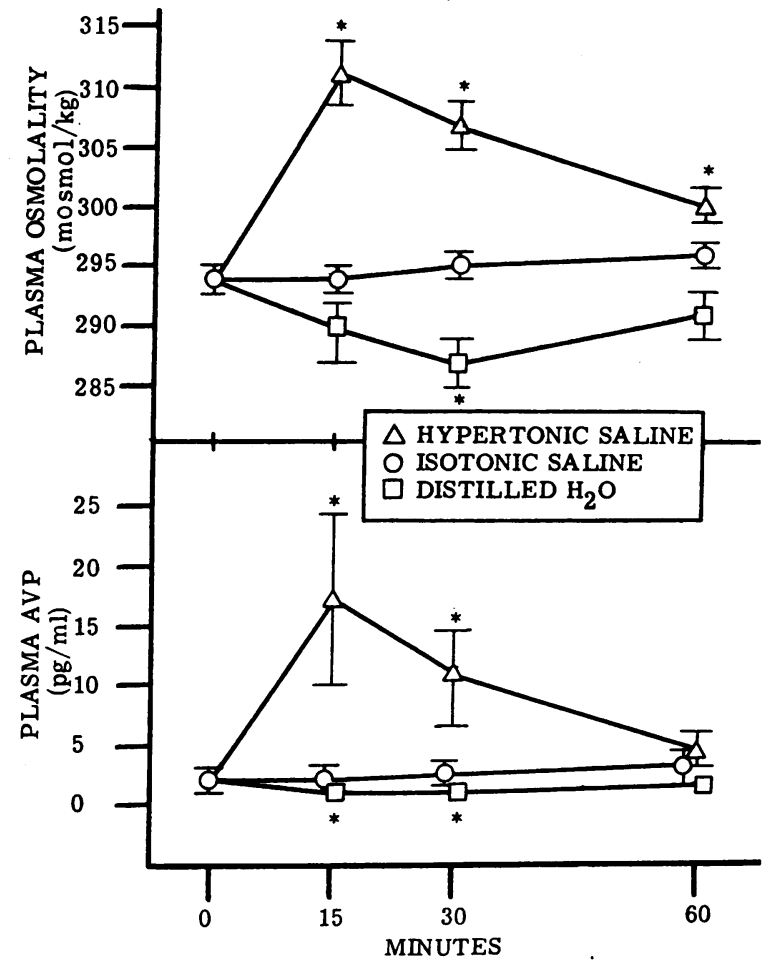

FIGURE 2 The effect of i.p. injections of distilled water, isotonic, or hypertonic saline on plasma osmolality and AVP. Rats were injected i.p. with $2 \mathrm{ml} / 100 \mathrm{~g}$ body wt of either distilled water, isotonic, (290 masmol/ $\mathrm{kg}$ ) or hypertonic $(1,000 \mathrm{mosmol} / \mathrm{kg})$ saline, sacrificed at 15,30 , or $60 \mathrm{~min}$, and the plasma osmolality, AVP, and hematocrit determined. Uninjected animals served as zero time controls. Mean blood hematocrit was $36.8 \%$ in control rats and $36.1 \%$ in rats sacrificed $30 \mathrm{~min}$ after hypertonic saline injection. The values shown for plasma osmolality and AVP at each time interval represent the mean and range of individual determinations on three animals. Asterisks indicate those values which differ significantly from zero time controls $(P<0.05$ by unpaired $t$-test $)$.

osmolality by freezing point depression (Advanced Instruments Osmometer, Model \#3L; Advanced Instruments, Inc., Needham Heights, Mass.). The remaining plasma was stored at $-20^{\circ} \mathrm{C}$ for $2-14$ days and the AVP concentration then determined by radioimmunoassay (2). This assay procedure can measure plasma AVP at concentrations as low as $0.5 \mathrm{pg} / \mathrm{ml}$ in sample volumes of $1 \mathrm{ml}$ and does not cross-react with oxytocin. The AVP in rat plasma appears to be immunologically stable when stored under the specified conditions.

Changes in blood volume (BV) were estimated from the changes in hematocrit ( $H c t)$ by the standard formula $(\mathrm{BV} 2 / \mathrm{BV} 1)=($ Hct1/Hct $) \times 100$ (3) which assumes no change in circulating erythrocyte volume.

All statistical computations were performed with the Statistics Package of the Hewlett-Packard desktop computer, model \#9810A (Hewlett-Packard Co., Palo Alto, Calif.). Linear regressions were determined by the method of least squares and evaluated for independence and for identity by conventional statistical methods (4). 


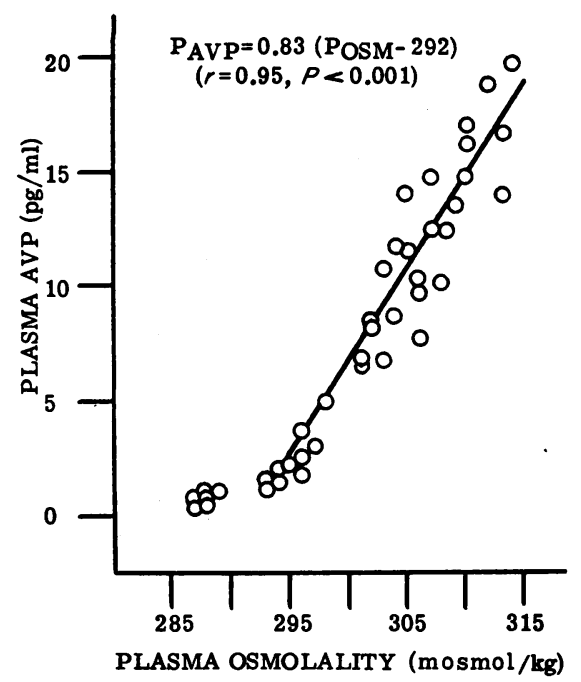

Figure 3 The relationship of plasma AVP to isovolemic changes in plasma osmolality. Rats were injected i.p. with $2 \mathrm{ml} / 100 \mathrm{~g}$ body wt of either distilled water, isotonic, (290 mosmol $/ \mathrm{kg})$ or hypertonic $(600,800,1,000$, or 1,200 mos$\mathrm{mol} / \mathrm{kg}$ ) saline, sacrificed $30 \mathrm{~min}$ later, and the blood hematocrit, plasma AVP, and osmolality determined. Each point represents the values obtained in a single animal. The regression values were calculated from only those samples with osmolalities greater than $292 \mathrm{mosmol} / \mathrm{kg}(n=35)$.

\section{RESULTS}

Effects of fluid deprivation. In 16 rats studied during ad lib intake of food and water, the blood hematocrit averaged $36.4 \pm 0.9 \%$, the plasma osmolality 293.6 $\pm 1.4 \mathrm{mosmol} / \mathrm{kg}$ and the plasma AVP concentration $2.3 \pm 0.9 \mathrm{pg} / \mathrm{ml}( \pm \mathrm{SD})$. Complete fluid restriction for

TABLE I

The Relationship of Plasma AVP to Osmolality in Normal Rats

\begin{tabular}{crccc}
\hline Date & $n$ & Intercept & Slope & $r$ \\
\hline $8 / 19 / 71$ & 10 & 292 & 1.2 & 0.93 \\
$9 / 21 / 71$ & 16 & 290 & 1.6 & 0.96 \\
$12 / 20 / 71$ & 14 & 290 & 0.9 & 0.96 \\
$2 / 15 / 72-\mathrm{A}$ & 8 & 292 & 1.9 & 0.98 \\
$-\mathrm{B}$ & 8 & 291 & 1.9 & 0.98 \\
$7 / 07 / 72$ & 10 & 293 & 1.3 & 0.94 \\
$8 / 24 / 72$ & 10 & 293 & 1.1 & 0.96 \\
\hline
\end{tabular}

All experiments were conducted essentially as described under Fig. 3, and the regression equation relating plasma AVP and osmolality for each group of rats calculated as described in the text. The values shown represent; the date each experiment was performed, the number of rats involved $(n)$, the intercept $(\mathrm{X}$-axis) and slope of the regression line, and the correlation coefficient for the relationship $(r)$. The data from $2 / 15 / 72$ were from two groups of rats from the same shipment that had been housed for one wk either in individual or group cages.

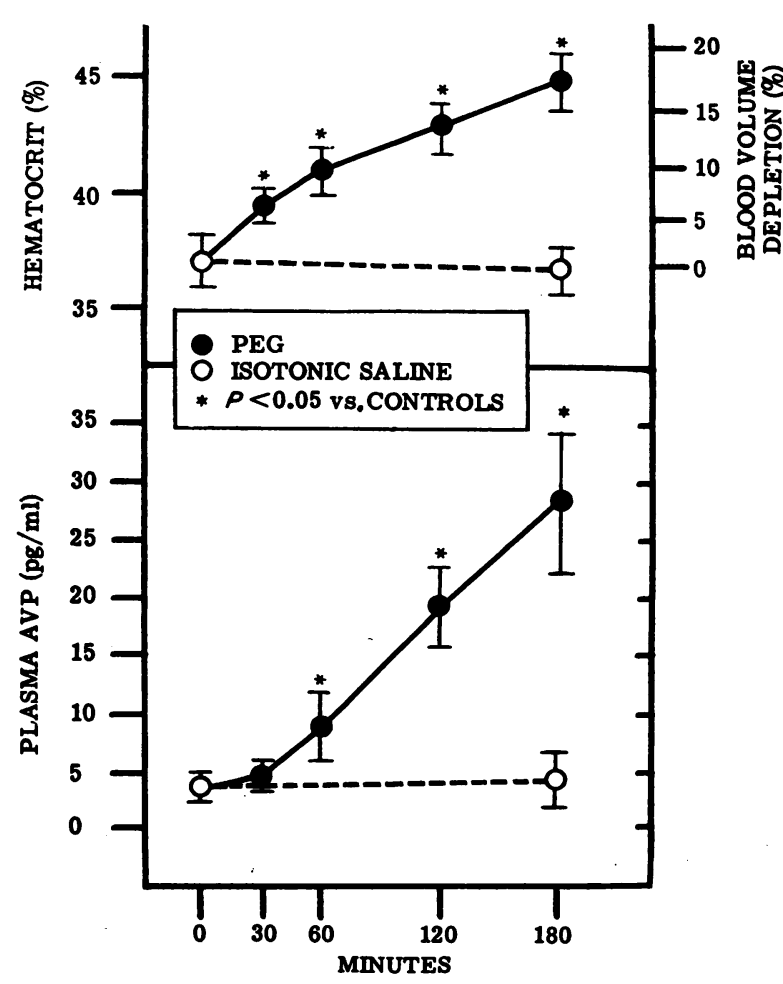

FIgure 4 The effect of i.p. injections of PEG on blood volume and plasma AVP. Experimental rats were injected i.p. with $2 \mathrm{ml} / 100 \mathrm{~g}$ body wt of isotonic saline containing PEG, at a concentration of $200 \mathrm{mg} / \mathrm{ml}$ and sacrificed at $30,60,120$, or $180 \mathrm{~min}$. Control animals received comparable amounts of isotonic saline alone. The levels of plasma AVP and blood hematocrit shown at each time interval represent the mean $\pm S D$ for five rats, and the asterisks indicate those values which differ significantly from the controls $(P<0.05$ by unpaired $t$-test $)$. The percent change in blood volume shown on the upper right-hand scale was calculated from the change in hematocrit values, relative to the mean basal level of $37 \%$ (see Methods). Mean ( \pm SD) plasma osmolalities in the control rats $(293.8 \pm 1.0 \mathrm{mosmol} / \mathrm{kg})$ and pooled experimental rats $(293.5 \pm 2.2 \mathrm{mosmol} / \mathrm{kg})$ were not significantly different $(P>0.4$ by unpaired $t$-test $)$.

periods of $12-96 \mathrm{~h}$ resulted in a progressive rise in each of the three variables to maximums of $49.0 \pm 2.4 \%$, $312.6 \pm 1.5 \mathrm{mosmol} / \mathrm{kg}$, and $23.1 \pm 4.9 \mathrm{pg} / \mathrm{ml}$, respectively (Fig. 1).

Effects of saline and distilled water injections. The i.p. injection of $2 \mathrm{ml} / 100 \mathrm{~g}$ body $\mathrm{wt}$ of hypertonic saline $(1,000 \mathrm{mosmol} / \mathrm{kg})$, resulted in a prompt and parallel rise in plasma osmolality and AVP, both of which peaked at $15 \mathrm{~min}$ and then declined at similar rates (Fig. 2). The injection of the same amount of distilled water was followed by an equally prompt fall in mean plasma osmolality to $287 \mathrm{mosmol} / \mathrm{kg}$ and in mean plasma AVP concentration to the barely detect- 
able level of $0.5 \mathrm{pg} / \mathrm{ml}$. The i.p. injection of isotonic saline did not significantly alter either plasma osmolality or AVP concentration.

The mean blood hematocrit in rats receiving hypertonic saline was about $1 \%$ lower than in the control rats. This change was not statistically significant for the relatively small number of samples involved in any one experiment, but analysis of pooled data from four such experiments $(n=36)$ revealed an overall fall in mean ( $\pm \mathrm{SD}$ ) blood hematocrit, from $37.7 \pm 1.0$ to 36.5 $\pm 1.5 \%$, that was significant $(P<0.05)$. The injection of isotonic saline had no appreciable effect on hematocrit.

When rats were injected i.p. with different concentrations of saline and sacrificed $30 \mathrm{~min}$ later, the resultant increase in plasma AVP was found to be directly proportional to the level of plasma osmolality achieved (Fig. 3). At osmolalities above $292 \mathrm{mosmol} /$ $\mathrm{kg}$, a precise, linear relationship $(r=0.95, P<0.001)$ between plasma AVP ( $\mathrm{P}_{\Delta \mathrm{VP}}$ ) and osmolality (Posm) was observed that was described by the regression equation $\mathrm{P}_{\Delta V \mathbf{P}}=0.83 \mathrm{Pos}_{\mathrm{M}}-242$. This equation could be rearranged to the more useful form $\mathrm{P}_{\mathrm{AVP}}=0.83$ (Posm -292 ), in which 0.83 represents the slope of the regression line, and 292 its intercept on the osmolality or X-axis. Representative values from six other such experiments conducted over a 12 mo period are shown in Table I. In all cases, the correlation coefficients were greater than 0.9 and the intercept on the osmolality axis very close to $292 \mathrm{mosmol} / \mathrm{kg}$. However, considerable variation in the slope of the regression line $(0.8-$ 1.9) was observed. This variability did not appear to follow a seasonal pattern nor to correlate with slight differences in the weight, diet, or housing arrangements of the animals.

Effects of polyethylene glycol (PEG) injections. The i.p. injection of isotonic saline containing PEG produced a rapid, progressive rise in hematocrit, without altering plasma osmolality (Fig. 4). This increase in hematocrit, which reflected a fall in plasma volume, was significant by $30 \mathrm{~min}$ and continued to increase for at least $3 \mathrm{~h}$. This was associated with a progressive rise in plasma AVP, but this rise was delayed and did not become significant until $1 \mathrm{~h}$ after the injection, by which time blood volume was calculated to have decreased by about $9 \%$.

When isotonic saline containing various concentrations of PEG were injected and the rats sacrificed $2 \mathrm{~h}$ later, a dose-related rise in hematocrit and plasma AVP was observed. In those animals in whom plasma osmolality remained at or near control levels (294 mosmol/ $\mathrm{kg}$ ), the increase in plasma AVP was related to the change in hematocrit, and hence blood volume, by a curvilinear function (Fig. 5). Significant increases in plasma AVP over control levels were observed only in those animals with an hematocrit greater than $39 \%$, which corresponded to a fall in blood volume of about $7 \%$. Beyond this point, $\mathrm{P}_{\Delta \mathrm{VP}}$ rose at an increasing rate relative to the degree of hypovolemia present. This relationship was best described by an exponential equation, $\mathrm{P}_{\Delta V \mathrm{P}}=1.3 e^{-0.17 \Delta v 01}$, in which $\mathrm{P}_{\triangle \mathrm{VP}}$ represents the plasma AVP concentration and $\Delta$ vol the percent change in blood volume as calculated from the change in hematocrits.

TABLE II

The Effect of Volume Depletion on Osmoreceptor Function

\begin{tabular}{|c|c|c|c|c|c|c|}
\hline Date & Treatment & $n$ & Regression equation & $r$ & Hematocrit & Volume \\
\hline & & & & & $\operatorname{mean} \pm S D$ & \% change \\
\hline \multirow[t]{3}{*}{$11 / 08 / 72$} & $\begin{array}{l}\text { Saline } \\
\text { Saline }+\end{array}$ & 18 & $P_{\mathrm{AVP}}=1.3\left(\mathrm{P}_{\mathrm{OSM}}-290\right)$ & 0.95 & $36.6 \pm 1.0$ & \\
\hline & PEG $(350 \mathrm{mg} / \mathrm{ml})$ & 14 & $\underline{P_{A V P}=1.8\left(P_{O S M}-284\right)}$ & 0.82 & $\underline{42.7 \pm 1.5}$ & $-14 \%$ \\
\hline & $P$ & & $<0.001$ & & $<0.001$ & \\
\hline \multirow[t]{3}{*}{$12 / 20 / 72$} & $\begin{array}{l}\text { Saline } \\
\text { Saline }+\end{array}$ & 8 & $\mathrm{P}_{\mathrm{AVP}}=0.9\left(\mathrm{P}_{\mathrm{OSM}}-293\right)$ & 0.90 & $35.8 \pm 0.4$ & \\
\hline & PEG $(200 \mathrm{mg} / \mathrm{ml})$ & 7 & $\underline{P_{A V P}}=1.4\left(P_{\text {OSM }}-293\right)$ & 0.85 & $\underline{38.0 \pm 0.9}$ & $-6 \%$ \\
\hline & $P$ & & $<0.01$ & & $<0.01$ & \\
\hline \multirow[t]{3}{*}{$1 / 24 / 73$} & $\begin{array}{l}\text { Saline } \\
\text { Saline }+\end{array}$ & 10 & $P_{A V P}=0.8\left(P_{\text {osM }}-289\right)$ & 0.96 & $35.7 \pm 1.4$ & \\
\hline & PEG $(225 \mathrm{mg} / \mathrm{ml})$ & 10 & $\underline{P_{A V P}=1.1\left(P_{\text {OSM }}-286\right)}$ & 0.82 & $\underline{38.8 \pm 1.3}$ & $-8 \%$ \\
\hline & $P$ & & $<0.01$ & & $<0.01$ & , \\
\hline
\end{tabular}

Experiments were conducted as described under Fig. 6 . The $P$ values refer to the difference between control and experimental values for the indicated parameters, 
HEMATOCRIT (\%)

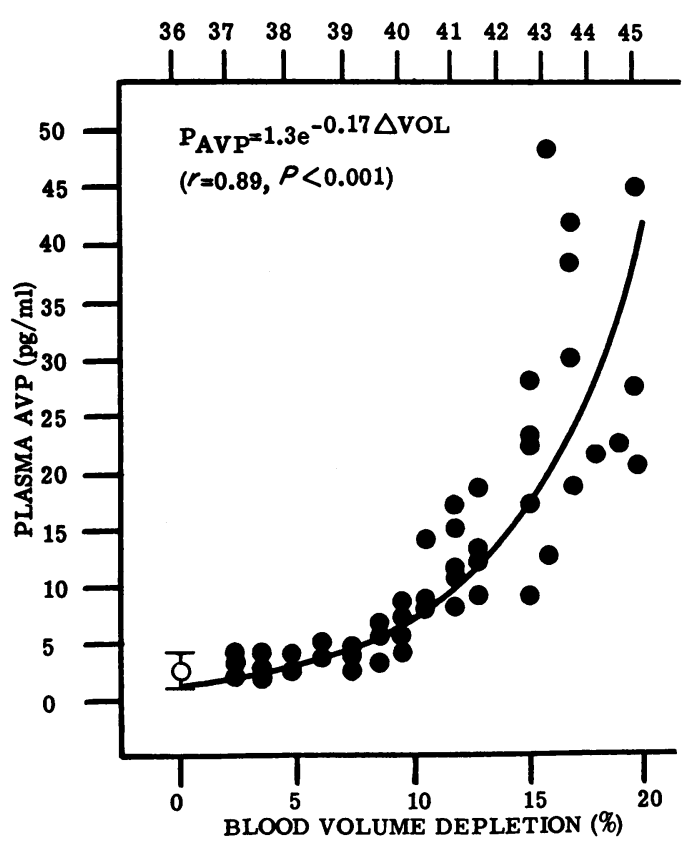

FIgUre 5 The relationship of plasma AVP to isosmotic changes in blood volume. Experimental rats were injected i.p. with $2 \mathrm{ml} / 100 \mathrm{~g}$ body wt of isotonic saline containing PEG at concentrations of $100,150,200$, or $250 \mathrm{mg} / \mathrm{ml}$. Control rats received the same amount of isotonic saline alone. All animals were sacrificed $2 \mathrm{~h}$ after the injection and plasma osmolality, AVP, and blood hematocrit determined. The mean $( \pm \mathrm{SD})$ plasma $\mathrm{AVP}$ and hematocrit for the control group were $2.4 \pm 0.9 \mathrm{pg} / \mathrm{ml}$ and $36.1 \pm 1.0 \%$, respectively. The plasma AVP value for each animal in the experimental group is plotted as a function of its blood hematocrit, shown on the upper scale, as well as the percent fall in blood volume to which it corresponds (see Methods). The mean $( \pm \mathrm{SD})$ plasma osmolalities in the control group $(293.5 \pm 1.7 \mathrm{mosmol} / \mathrm{kg} ; n=8)$ and pooled experimental group $(294.3 \pm 2.0 \mathrm{mosmol} / \mathrm{kg} ; n=48)$ were not significantly different $(P>0.3$ by unpaired $t$-test $)$.

Effects of injecting PEG with varying concentrations of saline. The i.p. injection of a constant amount of PEG dissolved in hypotonic, isotonic, or hypertonic saline resulted in a uniform rise in blood hematocrit in association with variable changes in plasma osmolality (Fig. 6). A close correlation between plasma AVP and osmolality was again seen in these PEGinjected rats, but the relationship differed quantitatively from that seen in the normovolemic controls. Thus, the injection of PEG in doses sufficient to reduce blood volume by about $6 \%$ was associated with a significant increase $(P<0.01)$ in the slope of the line relating plasma AVP to osmolality. A larger dose of PEG, which reduced blood volume by about $14 \%$, resulted in an even greater increase in the slope of the regression line as well as a reduction in the $\mathrm{X}$ - intercept or "osmotic threshold" for AVP release. Similar shifts in osmoregulatory function were seen in association with comparable levels of PEG induced hypovolemia in three other experiments (Table II).

\section{DISCUSSION}

Previous studies of the regulation of antidiuretic hormone suffer from a variety of methodologic limitations that often makes them difficult to interpret in physiologic terms. For the most part these studies were based on indirect or relatively insensitive measures of hormone activity, were concerned with the effects of relatively large stresses, and often were performed under anesthetics now known to have pronounced effects on antidiuretic hormone $(5,6)$. The present study was designed to avoid these problems by employing a sensitive and specific radioimmunoassay for plasma AVP to study hormone secretion under conditions that better approximate the usual physiological situation. The validity of the plasma AVP assay, documented previously for man (2), is further evidenced here by the good agreement with bioassay values reported for unanesthesized rats (6) as well as by the physiologic responses obtained.

Under basal conditions, plasma AVP was relatively constant, averaging $2.3 \pm 0.9 \mathrm{pg} / \mathrm{ml}$. This value is well above the sensitivity limit of our assay $(0.5 \mathrm{pg} / \mathrm{ml})$ and, since it did not seem to be affected by variations in laboratory environment nor by minor stresses such as the pain of injection, probably represents the true "basal" level. Nearly identical values are found in normally hydrated recumbent adult humans (2). As expected, fluid deprivation resulted in a very marked increase in plasma AVP as well as plasma osmolality and blood hematocrit (Fig. 1). This increase in AVP was readily detectable after only $12 \mathrm{~h}$ of fluid deprivation when plasma osmolality had increased by less than $2 \%$, and blood volume, as estimated from the change in hematocrit, had declined by a similar amount. These results amply document the extraordinary responsiveness of AVP secretion to small changes in water balance, but do not clarify whether the hormone response was due to the associated changes in osmolality, volume, or both. To resolve this question, it was necessary to employ other experimental approaches that permitted each of the two variables to be manipulated independently.

Fortunately for these purposes, we found that i.p. injection of hypertonic saline consistently produced a dose-related rise in plasma osmolality without appreciably altering total blood volume (Fig. 2). High concentrations of hypertonic saline ( $>900 \mathrm{mosmol} / \mathrm{kg}$ ) did cause a slight fall in mean hematocrit, but this effect was barely significant and represented a change in 
volume well below that normally required to affect AVP secretion (vide infra). Thus, the changes in plasma AVP which follow the injection of hypertonic saline, can be attributed almost exclusively to the changes in plasma osmolality. The validity of this conclusion is also supported by the close linear relationship between plasma AVP concentration and plasma osmolality after hypertonic saline injection (Fig. 3, Table I). In over a dozen such experiments conducted over a 12 mo period, the correlation coefficient for this relationship was never less than 0.9 , a result which testifies to the precision of the osmoreceptor mechanisms that govern AVP secretion. The constancy of this mechanism is shown by the point of intercept of the various regression lines on the $\mathrm{X}$ or osmolality axis (Table I). This value, which represents the "threshold" for the osmotically mediated release of AVP, was remarkably constant from one group of rats to the next, averaging about $292 \mathrm{mosmol} / \mathrm{kg}$. Thus, "basal" plasma osmolality, which was also quite constant at about $294 \mathrm{mosmol} / \mathrm{kg}$, appears to be maintained, probably by the thirst mechanism, only slightly above the osmotic threshold for AVP release.

The sensitivity of this osmoregulatory system is represented by the slope of the regression lines relating plasma AVP to osmolality (Fig. 3, Table I). Although this parameter was less constant from experiment to experiment than the threshold values, a slope of less than 0.8 has been observed only once in normal rats. This means that an increase in plasma osmolality of only $1 \%(2.9 \mathrm{mosmol} / \mathrm{kg})$ regularly resulted in a rise in plasma AVP of at least $2.4 \mathrm{pg} / \mathrm{ml}$, a result that amply confirms Verney's original conclusion concerning the sensitivity of this osmoregulatory system (7). The reason for the apparent variability in osmoreceptor sensitivity is unclear. It did not seem to follow a seasonal pattern nor to be influenced by variations in the housing arrangements for the animals (Table I). Recent studies in our laboratory suggest that osmoreceptor sensitivity may be subject to some circadian variation but this factor alone cannot account for the differences observed here.

To evaluate the characteristics of the volume-related control systems, it was necessary to employ a technique that would produce small, readily quantifiable reductions in blood volume without altering plasma osmolality. A further requirement was that the procedure not cause undue stress and, therefore, not require the use on anesthesia. We have found that the i.p. injection of saline solutions of PEG is well suited to this purpose. PEG is a nonabsorbable hydrophilic polymer which, when injected i.p., results in a transudation of noncolloid water from the extracellular into the peritoneal space $(8)$. This leads to a rapid fall in

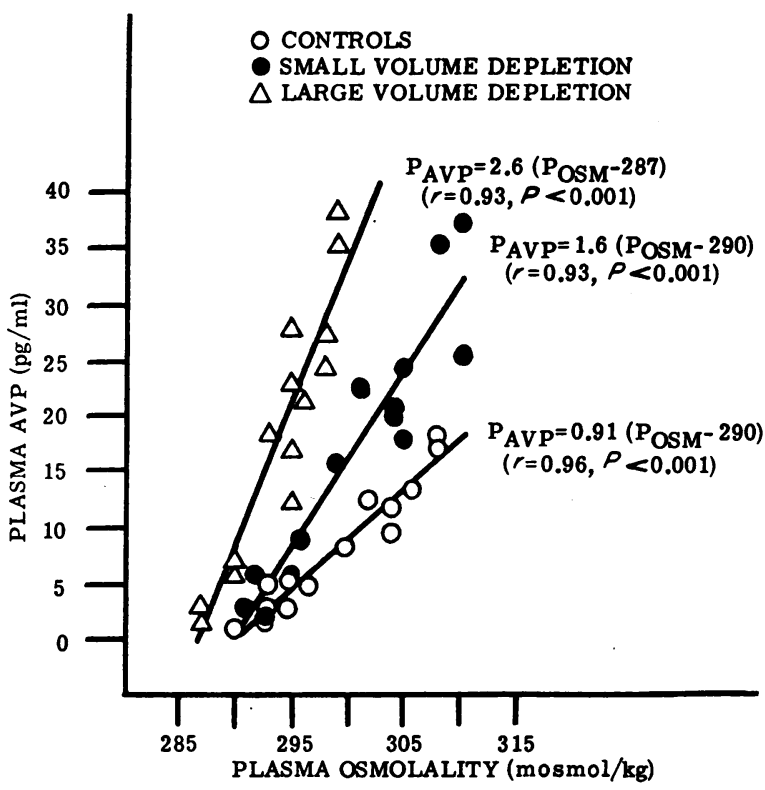

FIGURE 6 The effect of hypovolemia on the plasma AVP response to osmotic stimulation. One group of rats was injected i.p. with $2 \mathrm{ml} / 100 \mathrm{~g}$ body wt of either isotonic (290 mosmol $/ \mathrm{kg}$ ) or hypertonic (600 or $900 \mathrm{mosmol} / \mathrm{kg}$ ) saline containing PEG at a concentration of $200 \mathrm{mg} / \mathrm{ml}$. A second group received the same amount of either distilled water or isotonic saline containing PEG at a concentration of $350 \mathrm{mg} / \mathrm{ml}$. The control group received either isotonic or hypertonic saline without PEG. All rats were sacrificed $30 \mathrm{~min}$ after injection and the plasma osmolality, $\mathrm{AVP}$, and hematocrit determined. Mean blood hematocrit in rats injected with $200 \mathrm{mg} / \mathrm{ml}$ PEG showed a small but statistically significant increase $(P<0.05$ by unpaired $t$ test) over that in rats injected with saline alone (39.6 $\pm 0.7 \%$ vs. $37.1 \pm 1.2 \%$ ), corresponding to a decline in mean blood volume of $6.3 \pm 1.6 \%( \pm S D)$ (small volume depletion). The rats injected with $350 \mathrm{mg} / \mathrm{ml} \mathrm{PEG} \mathrm{had}$ a greater increase in hematocrit, to $43.4 \pm 0.6 \%$, corresponding to a decline in mean blood volume of $14.5 \pm 1.2 \%$ (士SD) (large volume depletion). The regression line relating plasma AV.P and plasma osmolality in the control group differed significantly from that for both the small volume $(t=3.66 ; P<0.001)$ and large volume $(t=4.26$; $P<0.001)$ depletions.

plasma volume, and hence blood volume, which can be easily quantified from the resultant rise in hematocrit. The degree of hypovolemia produced can be controlled by varying either the duration of the injection (Fig. 4) or the concentration of PEG employed (Fig. 5), while the effect on plasma osmolality can be regulated by varying the concentration of saline in which the PEG is dissolved (Fig. 6).

With this approach it has been possible to show that the effects of hypovolemia on AVP secretion differ qualitatively as well as quantitatively from those of hyperosmolarity. Unlike the prompt response seen after hypertonic saline injection (Fig. 1) the rise in plasma 


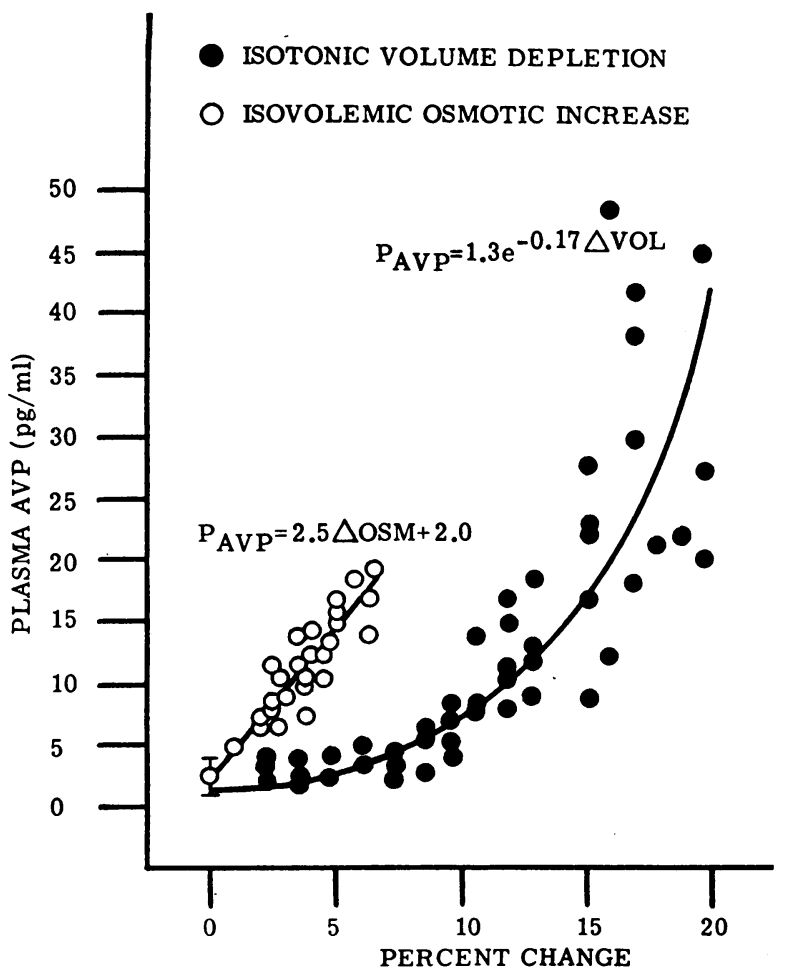

FIGURE 7 The relationship of plasma AVP to percent change in plasma osmolality and blood volume. The data shown are from the experiments described under Figs. 3 and 5. The percent change in plasma osmolality ( $\triangle O S M$ ) was calculated relative to the mean basal level of 294.4 $\pm 1.4 \mathrm{mosmol} / \mathrm{kg}$. The percent change in blood volume $(\triangle \mathrm{VOL})$ was calculated relative to mean basal hematocrit as previously described. Each point represents one animal.

AVP after PEG injection occurred relatively late, well after the hypovolemia had progressed to substantial levels (Fig. 4). This lag in AVP release can be attributed to the exponential nature of the stimulusresponse curve that characterizes the effects of isotonic volume depletion (Fig. 5). Thus, hypovolemia was not an effective stimulus to AVP release unless the fall in volume exceeded $8-10 \%$ of normal. The 2 -fold rise in plasma AVP observed at this level of hypovolemia is very similar to that found in two other studies, also conducted without anesthesia, that used phlebotomy to reduce blood volume. Henry, Gupta, Meehan, Sinclair, and Share found that a $10-15 \%$ reduction in the blood volume of a dog resulted in a 2 -fold rise in plasma antidiuretic activity (9), while Johnson, Zehr, and Moore observed a similar increase in plasma antidiuretic activity after removing $10 \%$ of the blood volume of a sheep (10). Although the basis for comparison is rather limited, the agreement between these two studies and our own results suggests that the PEG method for producing and quantitating blood volume changes in the rat is directly comparable to other types of volume depletion. This conclusion is also supported by preliminary studies in man where it has been found that removal of up to $6 \%$ of blood volume by phlebotomy has no effect on plasma AVP (11).

When compared on the basis of percent change from basal levels, it is readily apparent that small changes in blood osmolality are much more effective than small changes in volume in altering AVP secretion (Fig. 7). Due to the exponential nature of the hypovolemic response, however, very large increases in plasma AVP can be produced more readily by reducing volume than by raising osmolality. The present studies demonstrate that this is not necessarily synonymous with the primacy of volume in regulating AVP secretion, as previously has been suggested (12).

Our studies also confirm and extend a previous observation that hypovolemia does not abolish the influence of osmolality on AVP secretion (10). Instead, hypovolemia appears to modify osmoregulatory function in such a way as to promote increased AVP release in response to a given level of plasma osmolality (Fig. 6, Table II). The mechanisms of this effect, which manifest both a reduction in the threshold and an increase in the slope of the osmoreceptor response, are unknown. The studies of Gauer and Henry (13) and Share (14) indicate that the effects of large volume depletions on AVP secretion are mediated, at least in part, by afferent nerves from pressure-sensitive receptors in the heart and large arteries of the chest and neck. However, recent reports on the effects of angiotensin on AVP secretion $(15,16)$ raise the possibility that a humoral mechanism might also be involved. It is conceivable that each of the two parameters of osmoreceptor function-threshold and sensitivity-is responsive to a different volume-sensitive system, one humoral and the other nervous.

We conclude that in the usual physiologic situation, such as a short period of fluid deprivation, the major stimulus to AVP secretion must be the resultant rise in blood osmolality, since the accompanying changes in volume are usually not of sufficient magnitude to be effective. Thus, the $2 \%$ decline in blood volume observed in our rats after $12 \mathrm{~h}$ of fluid deprivation could not by itself have caused the observed rise in plasma AVP, whereas the $1.5 \%$ rise in osmolality could easily have had this effect. During longer periods of fluid deprivation, however, the progressive fall in blood volume probably plays a more important role in maintaining AVP secretion. Under these conditions, neurohypophyseal stores of AVP decline progressively to less than one-third normal levels (17), a circumstance that should result in a corresponding fall in the amount of AVP released in response to a given stimulus (18). 
The fact that a decrease in the plasma AVP-osmolality relationship was not observed after prolonged fluid restriction (the relationship was quite similar to that after hypertonic saline injection) indicates enhancement of the osmotically mediated AVP secretion by the accompanying hypovolemia. This booster effect thus serves to insure the secretion of AVP in amounts sufficient to maintain maximum antidiuresis during prolonged water deprivation despite profound depletion of pituitary stores of the hormone.

\section{ACKNOWLEDGMENTS}

The authors gratefully acknowledge the invaluable technical assistance of Mary E. Pratt in these studies.

This work was supported by grants from the Veterans Administration Designated Research Funds (G. L. R.), U. S. Public Health Service-GRSG FR-5369, Veterans Administration Training Grant in Endocrinology and Metabolism, TR-88, and U. S. Public Health Service Grants 5369 and AMO-5173.

\section{REFERENCES}

1. Sawyer, W. H., and E. Mills. 1966. Control of vasopressin secretion. In Neuroendocrinology. L. Martini and W. F. Ganong, editors. Academic Press, Inc., N. Y. 187.

2. Robertson, G. L., E. A. Mahr, S. Athar, and T. Sinha. 1973. The development and clinical application of a new radioimmunoassay for arginine vasopressin in human plasma. J. Clin. Invest. 52: 2340.

3. Documenta Geigy Scientific Tables. 1970. K. Diem and C. Lenter, editors. J. R. Geigy, Basle. 7th edition. 554.

4. Documenta Geigy Scientific Tables. 1970. K. Diem and C. Lenter, editors. J. R. Geigy, Basle. 7th edition. 177.

5. Ginsburg, M., and L. M. Brown. 1956. Effects of anaesthetics and haemorrhage on the release of neurohypophysial antidiuretic hormone. Br. J. Pharmacol. Chemother. $11: 236$
6. Little, J. B., and E. P. Radford. 1964. Bioassay for antidiuretic activity in blood of undisturbed rats. $J$. Appl. Physiol. 19: 179.

7. Verney, E. B. 1947. Croonian Lecture: the antidiuretic hormone and factors which determine its release. Proc. R. Soc. Lond. B. Biol. Sci. 135: 25

8. Brenner, B. M., and R. W. Berliner. 1969. Relationship between extracellular volume and fluid readsorption by the rat nephron. Am. J. Physiol. 217: 6 .

9. Henry, J. P., P. D. Gupta, J. P. Meehan, R. Sinclair, and L. Share. 1968. The role of afferents from the low-pressure system in the release of antidiuretic hormone during nonhypotensive hemorrhage. Can. J. Physiol. Pharmacol. $46: 287$.

10. Johnson, J. A., J. E. Zehr, and W. W. Moore. 1970. Effects of separate and concurrent osmotic and volume stimuli on plasma ADH in sheep. Am. J. Physiol. 218: 1273 .

11. Robertson, G., and E. A. Mahr. 1972. The importance of plasma osmolality in regulating antidiuretic hormone secretion in man. J. Clin. Invest. 51: 79a.

12. Saito, T., and S. Yoshida. 1971. Levels of antidiuretic hormone in plasma after hemorrhage and infusion of hypertonic saline in dogs. Endocrinology. 88: 1511.

13. Gauer, O. H., and J. P. Henry. 1963. Circulatory basis of fluid volume control. Physiol. Rev. 43: 423

14. Share, L. 1969. Extracellular fluid volume and vasopressin secretions. In Frontiers In Neuroendocrinology. W. F. Ganong and L. Martini, editors. Oxford University Press, New York. 183.

15. Andersson, B., and O. Westbye. 1970. Synergistic action of sodium and angiotensin on brain mechanisms controlling fluid balance. Life Sci., Part I. Physiol. Pharmacol. 9: 601 .

16. Malvin, R. L. 1971. Possible role of the renin-angiotensin system in the regulation of antidiuretic hormone secretion. Fed. Proc. 30: 1383.

17. Moses, A. M., and M. Miller. 1970. Accumulation and release of pituitary vasopressin in rats heterozygous for hypothalamic diabetes insipidus. Endocrinology. 86: 34.

18. Miller, M., and A. M. Moses. 1971. Radioimmunoassay of urinary antidiuretic hormone with application to study of the Brattleboro rat. Endocrinology. 88: 1389. 